\title{
Morphology Changes and Fillers Migration in Urethane Composites during Thermal Degradation
}

\author{
Atsuki Tanifuji ${ }^{1}$, Takato Ishida ${ }^{2}$ and Ryoma Kitagaki ${ }^{1}$ \\ ${ }^{1}$ Graduate School of Engineering, Division of Human Environmental Systems, Hokkaido University, \\ Kita 13-Nishi 8, Kita-ku, Sapporo, Hokkaido 060-8628, Japan, atsuki_123@eis.hokudai.ac.jp \\ ${ }^{2}$ Graduate School of Engineering, Division of Human Environmental Systems, Hokkaido University, \\ Kita 13-Nishi 8, Kita-ku, Sapporo, Hokkaido 060-8628, Japan, takato.matphysichem@gmail.com \\ ${ }^{3}$ Graduate School of Engineering, Division of Human Environmental Systems, Hokkaido University, \\ Kita 13-Nishi 8, Kita-ku, Sapporo, Hokkaido 060-8628, Japan, ryoma@eng.hokudai.ac.jp
}

\begin{abstract}
Polyurethane composite coatings are frequently applied to strengthen the barrier properties of various construction materials such as wood, metal and concrete. The changes of color and glossiness of the composite coatings for building materials proceeds more slowly than that of polyurethane because of containing fillers and several types of additives. However, the most critical barrier properties have not been studied directly based on the difference from the degradation mechanism of polyurethane coatings. Additionally, the difference in thermal and UV degradation mechanisms of coatings is not clear in the existing studies dealing with conventional accelerated weathering tests and outdoor exposure tests. Therefore, the behavior of the filler contained in the coatings was observed using an oven to accelerate thermal degradation. The chemical analysis of the coating surface by XPS and the analysis of the images and elemental mappings by SEM-EDS were carried out, and the mechanism of degradation progress was investigated. In addition, the temperature dependency of the degradation was studied in changing the heating temperature. It was suggested that polymer and fillers interact in promoting mass transfer at the same time as the thermal degradation reaction consequently.
\end{abstract}

Keywords: Building Material, Coating, Filler, Polymer, Thermal Degradation.

\section{Introduction}

Building material products used for topcoat contain so many chemical materials and consist of chemically complex systems. The products contain polyurethane, polyacrylic, modified silicone, and hybrid polymers. Furthermore, their products contain plasticizers, additives, and inorganic fillers in order to ensure performance and durability (Annamalai Pratheep Kumar et. al. (2009), D.K. Chattopadhyay (2006), Ivan S. Stefanović et. al. (2019), Jun Liu et. al. (2017), Li Bin (2014), M.Sabzi et. al. (2008) and S.M. Mirabedini (2013)).

In the present circumstances, the degradation process of coating materials containing polymers and inorganic substances has not been discussed. Even manufacturing companies have difficulty in elucidating their degradation mechanism, because such companies purchase raw materials from other companies and mix them to make products in many cases. In addition, there are few studies that separate thermal degradation from UV degradation through accelerated weathering tests and outdoor exposure tests. Therefore, this paper examines thermal degradation mechanism of coatings based on the result of the chemical analysis of the coating surface by XPS and the analysis of the images and elemental mappings by SEM-EDS. 


\section{Methods}

\subsection{Samples}

In this study, both thermally-degraded and non thermally-degraded samples were prepared. The Conventional two-component type urethane coating including $\mathrm{TiO}_{2}, \mathrm{CaCO}_{3}$, and $\mathrm{BaSO}_{4}$ as fillers was coated on a slide glass with a spin coater to control film thickness. After the surfaces of the samples were sufficiently dried, they were cured for 120 days at $20^{\circ} \mathrm{C}$ and $60 \%$ relative humidity, and cut to $7 \mathrm{mmX} 7 \mathrm{~mm}$ for fitting measuring instruments.

Subsequently, the samples after cutting were heat-degraded at $30^{\circ} \mathrm{C}, 50^{\circ} \mathrm{C}$, and $70^{\circ} \mathrm{C}$. The periods of the degradation are $0,1,3$, and 7 days, and XPS measurement and SEM-EDS measurement were conducted respectively. The features of the measurements are briefly shown in Table 1.

\subsection{XPS Measurement}

X-ray photoelectron spectroscopy (XPS) was used to evaluate the chemical properties of urethane resin coatings. This technique is applied to analyze the type, concentration, and chemical state of elements on sample surfaces. Each sample is irradiated with an X-ray source using $\mathrm{Mg}-\mathrm{K} \alpha$ rays, and wide spectrums with a binding energy in the range of 10 to $1000 \mathrm{eV}$ and narrow spectrums around the peak of each detected element was obtained at a measurement

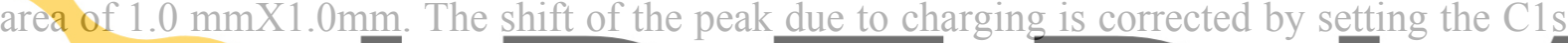

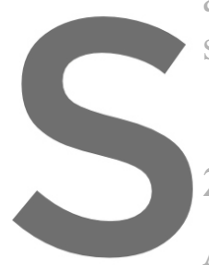
spectrum to $284.0 \mathrm{eV}$, and correction using a neutralizing electron gun is not performed.

\subsection{SEM-EDS Observation}

A scanning electron microscone
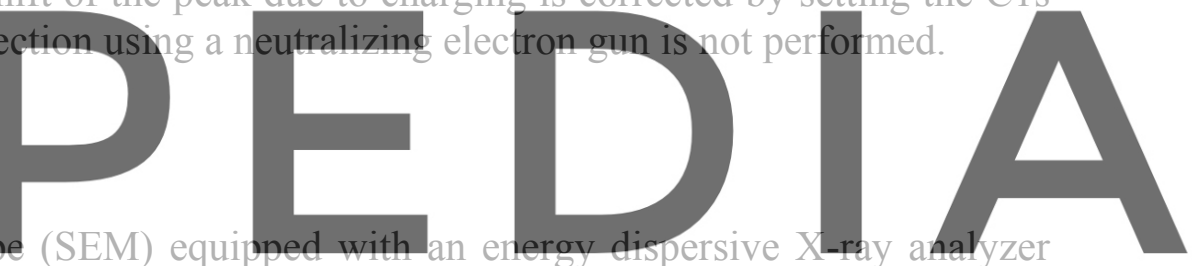

(EDS) was applied due to analyze the elemental information of the cross section of the samples.

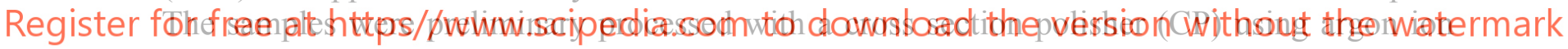
beam for cross sectional observation.

In addition, the surfaces of the samples were coated with Au by ion sputtering to avoid thermal degradation of the samples.

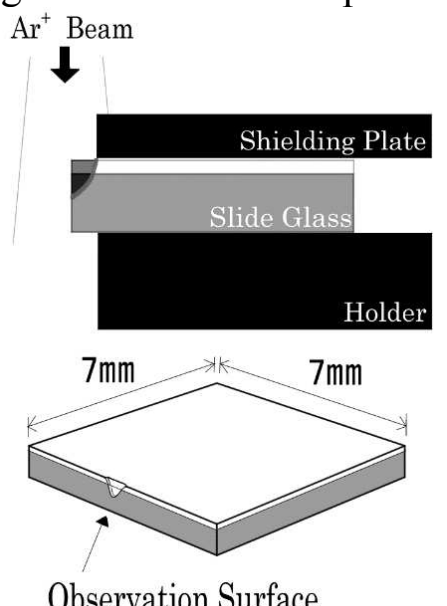

Table 1. Survey contents in each method.

Observation Surface

\begin{tabular}{|c|c|c|}
\hline \multirow{2}{*}{ XPS } & \multicolumn{2}{|c}{$\begin{array}{c}\text { History of elemental type and } \\
\text { chemical bonding state of coating } \\
\text { surface layer }\end{array}$} \\
\hline \multirow{2}{*}{$\begin{array}{c}\text { SEM- } \\
\text { EDS }\end{array}$} & $\begin{array}{c}\text { SEM } \\
\text { image }\end{array}$ & $\begin{array}{l}\text { - Cross section } \\
\text { thickness of coating } \\
\text { - Filler particle size }\end{array}$ \\
\cline { 2 - 4 } & $\begin{array}{c}\text { Elemental } \\
\text { mapping }\end{array}$ & $\begin{array}{l}\text { Distribution of } \\
\text { elements in the cross } \\
\text { section of coating } \\
\text { film and its history }\end{array}$ \\
\hline
\end{tabular}

Figure 1. Processing before sample observation. 


\section{Results}

\subsection{XPS Scans}

Figure 2 shows XPS narrow scan spectra of the urethane resin coatings that were thermally degraded at $70^{\circ} \mathrm{C}$ for $0,1,3$, and 7 days. The peak of $\mathrm{O} 1 \mathrm{~s}, \mathrm{~N} 1 \mathrm{~s}$, and Si-O increased as thermal degradation treatment continued. This result could be explained that the polymer such as urethane and siloxane was decomposed and appeared on the surface layer of the coatings due to low molecular weight and low density. On the other hand, the Ca peak was hardly detected on the surface layer. This result indicates that the substance in the coating may move up and down dramatically before the surface of the coating is cracked while the coating is thermally degraded. The fillers such as $\mathrm{CaCO}_{3}$ originally floating on the surface of the coating film could be sunk as the polymers were scattered and float by heat.

Figure 3 shows $\mathrm{O}$ spectra of the samples that were thermally degraded at $30^{\circ} \mathrm{C}$ and $50^{\circ} \mathrm{C}$ for the same period. The graph shows that the peak increase on the 1 st to 7 th days at $30^{\circ} \mathrm{C}$, however at $50^{\circ} \mathrm{C}$, it increases on the 1 st and 3 rd days and decreases on the 7 th day. These tendencies suggest the possibility of different thermal oxidation reactions on the coating surface, such as increases in $\mathrm{C}-\mathrm{O}$ and $\mathrm{C}=\mathrm{O}$ bonds and a decrease in $\mathrm{O}$ due to the progress of $\mathrm{C}$ crosslinking. Furthermore, each thermal oxidation reaction takes place at different times during the process of thermal degradation.
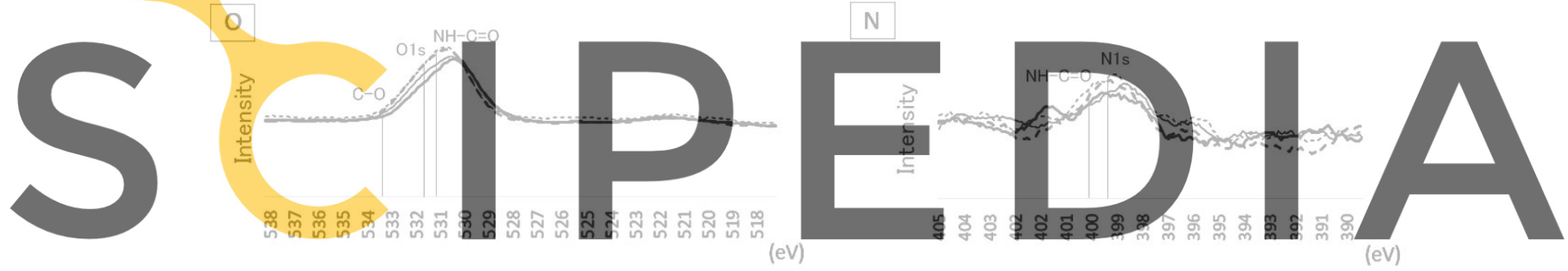

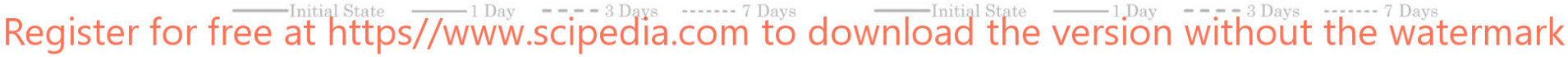

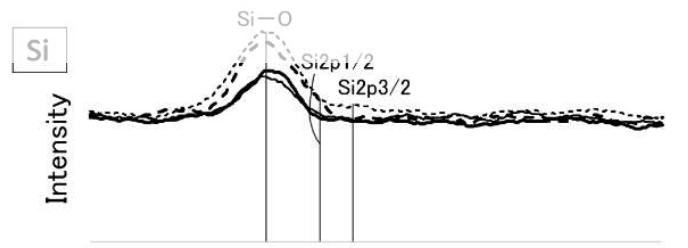

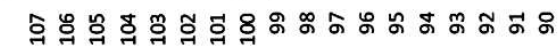

(ev)

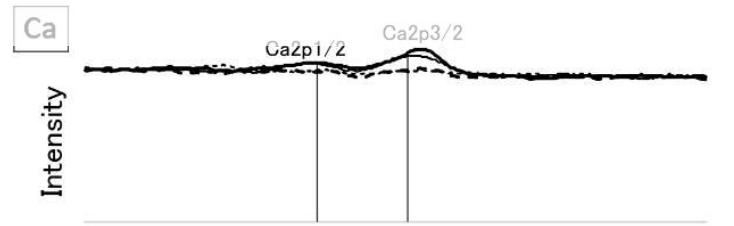

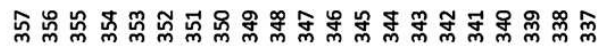

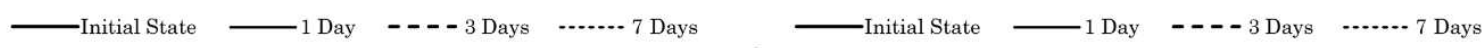

Figure 2. Narrow scan spectra of the urethane resin coatings that were thermally degraded at $70^{\circ} \mathrm{C}$. 

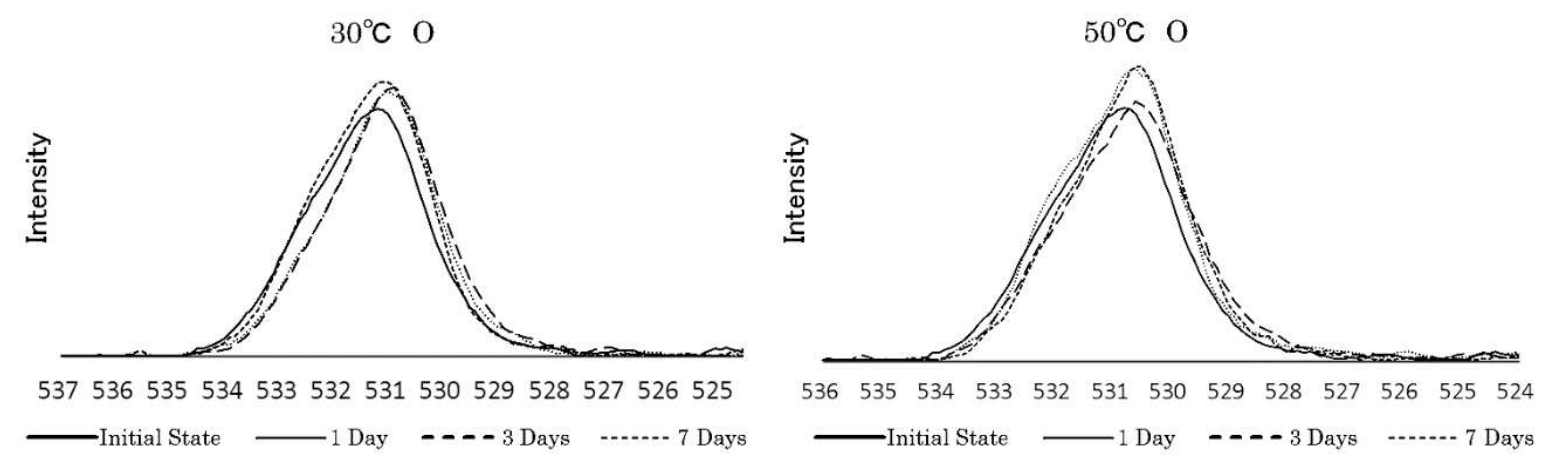

Figure 3. $\mathrm{O}$ spectra of the urethane resin coatings that were thermally degraded at $30^{\circ} \mathrm{C}$ and $50^{\circ} \mathrm{C}$.

\subsection{SEM Images}

Figure 4 shows the film thickness history of each sample obtained from SEM image of the sample thermally degraded for $0,1,3$, and 7 days, respectively, at $30^{\circ} \mathrm{C}, 50^{\circ} \mathrm{C}$, and $70^{\circ} \mathrm{C}$. However, it should also be noted that samples exposed at $70^{\circ} \mathrm{C}$ and samples at $30^{\circ} \mathrm{C}$ or $50^{\circ} \mathrm{C}$ are different in initial states. In the non thermally-degraded sample, the thickness of the coating was approximately $60 \mathrm{~mm}$. The thickness of coating gradually decreased due to heat degradation at $70^{\circ} \mathrm{C}$, and was $38 \mathrm{~mm}$ on $1^{\text {st }}$ day, $18 \mathrm{~mm}$ on $3^{\text {rd }}$ day, and $10 \mathrm{~mm}$ on $7^{\text {th }}$ day. The coating thickness decreased due to thermal decomposition and volatilization of components

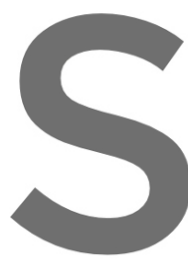
such as plasticizers in increased slightly, and at of the coating could be to changes of gel structur et. al. (2017)).
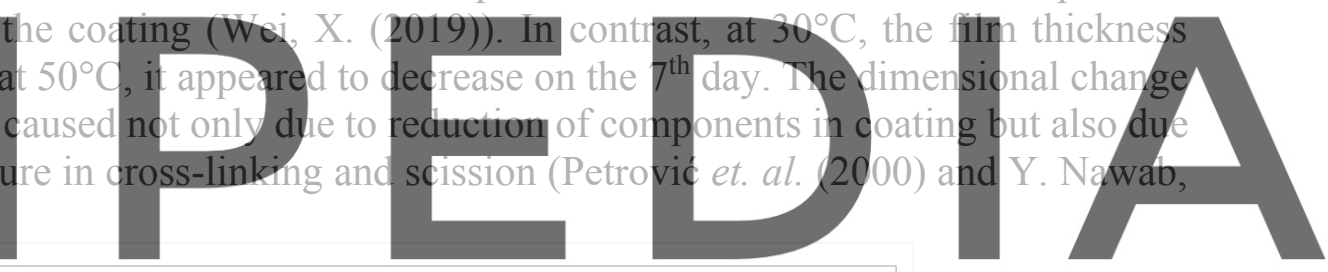

Register for free at https//www.scipedia.com to download the version without the watermark

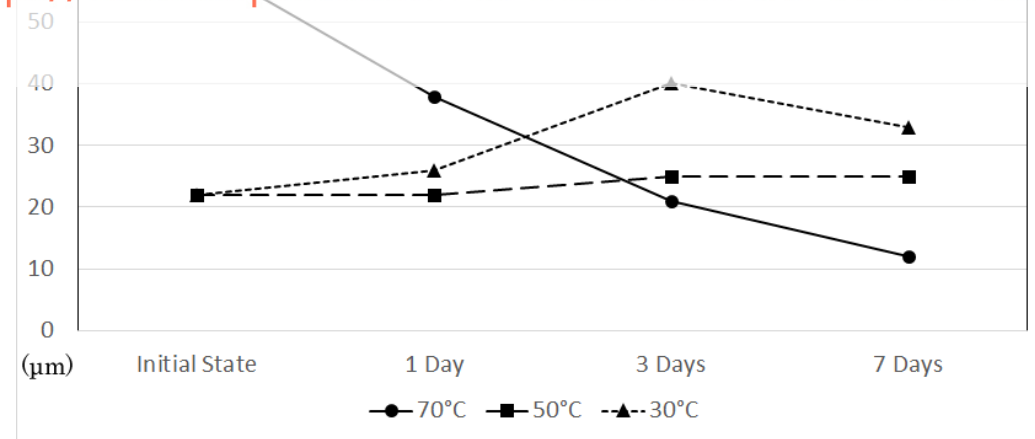

Figure 4. Changes in film thickness of each sample.

\subsection{Elemental Mappings}

Figure 5 shows the history of element mapping of Ti. Ti was homogeneous in the initial state, increased at the bottom on the first day, and gradually increased on the surface over time by heating at $50^{\circ} \mathrm{C}$. On the first day, fillers move to the bottom of the coating as polymers become 
smaller and less dense due to thermal decomposition. From the third day, filler have been pushed up from the bottom due to polymer cross-linking and polymerization reaction (Wei, X., et. al. (2019)).

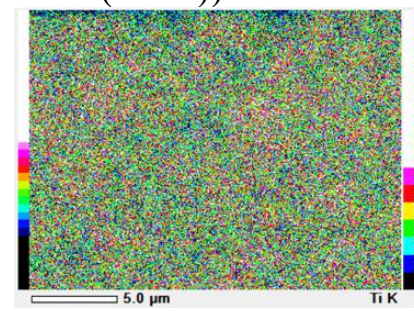

Initial State

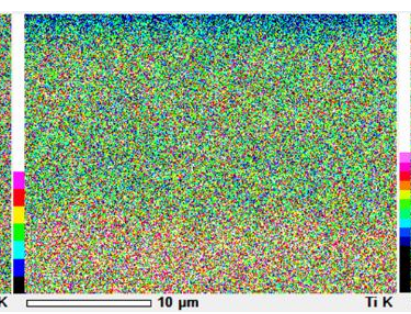

1 Day

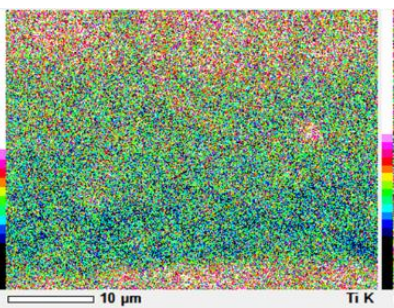

3 Days

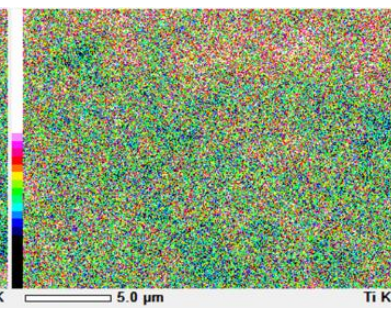

7 Days

Figure 5. Sectional elemental mapping of Ti in urethane composite coatings at $50^{\circ} \mathrm{C}$.

\section{Discussion}

\subsection{Temperature Dependence of Coating Durability}

\section{The coating thickness increased initially at lower temperatures and decreased at higher} temperatures, accompanied by the movement of the filler. Since fillers such as titanium dioxide have a role to protect the coating from UV degradation, the durability of the construction coating could vary greatly due to differences in temperature history.
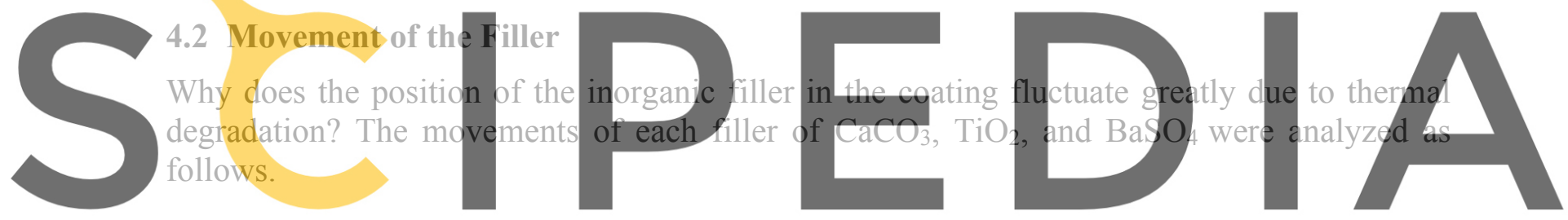

\subsection{1 $\mathrm{CaCO}_{3}$}

Register for free, at https/fwww. scipedia.com to download the yersion without the watermark

decreases depending on the temperature. There was no significant movement of $\mathrm{CaCO}_{3}$ contained in the coating as a filler, and the XPS Ca peak changed due to a change in the state of the surface layer of the coating. The decrease in the Ca peak at $70^{\circ} \mathrm{C}$ could indicate that the surface layer became smoother and covered with polymer as the temperature of the coating approached the glass transition temperature (L.S De Bernarde, et. al. (1984)).

\subsection{2 $\mathrm{TiO}_{2}$ and $\mathrm{BaSO}_{4}$}

XPS peaks of titanium and barium were not detected, however in elemental mapping by SEMEDS, there were dramatic movements in the coating as shown in Figure 5. Moreover, the movement tendency of the position of the two elements is very similar and corresponds to the movement of $\mathrm{TiO}_{2}$ and $\mathrm{BaSO}_{4}$ in the coating as fillers. These fillers could move shrinkage stress due to polymerization, expansion stress due to heating, and stress due to movement of the polymer having a low molecular weight. The positions of these fillers are inhomogeneous unlike CaSO4, because the stress from the polymer may differ depending on the particle size of the filler (Nabil Hayeemasae et. al. (2018)). However, understanding these mechanisms require further studies. 


\section{Conclusions}

- The position of the fillers contained in the organic composite coating are inhomogeneous due to thermal degradation.

- Polymerization, scission and cross-linking of the polymers can be accelerated by the action of heat, which can affect the thickness of the coating.

- The cross-sectional morphology of the coating changes depending on the temperature of thermal degradation.

- Changes in thickness and inhomogeneous distribution of materials due to thermal degradation of architectural composite coatings could affect their barrier performance because of the movements of the fillers and changes of the thickness.

\section{ORCID}

Atsuki Tanifuji: http://orcid.org/0000-0003-4363-5834

Takato Ishida: http://orcid.org/0000-0003-3919-2348

Ryoma Kitagaki: http://orcid.org/0000-0001-6001-3688

\section{References}

Annamalai Pratheep Kumar, Dilip Depan, Namrata Singh Tomer and Raj Pal Singh (2009). Nanoscale particles for polymer degradation and stabilization-Trends and future perspectives, Progress in Polymer Science, Volume 34, Issue 6, June 2009, Pages 479-515

D.K. Chattopadhyay and K.V.S.N. Raju (2006). Structural engineering of polyurethane coatings for high performance application

Ivan S. Stefanović, Jasnin Marković and Marija dioxide nanocomposites,

Jun Liu, Youyuan Wang, LDPE/TiO2 Nanocompos
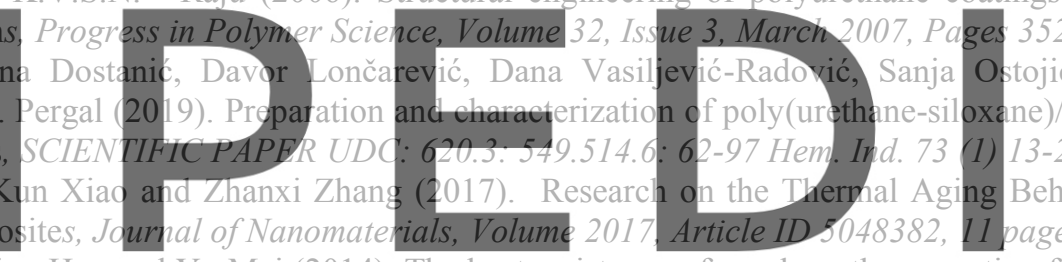
modified nano-CaCO3, Applied Surface Science, Volume 315. I October 2014, Pages 24.1-246

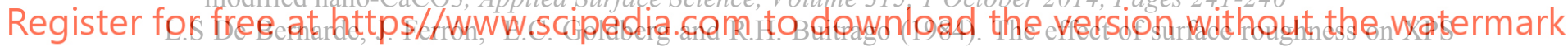
and AES, Volume 139, Issues 2-3, 2 April 1984, Pages 541-548

M.Sabzi, S.M.Mirabedini, J.Zohuriaan-Mehr and M.Atai (2008). Surface modification of TiO2 nano-particles with silane coupling agent and investigation of its effect on the properties of polyurethane composite coating, Progress in Organic Coatings, Volume 65, Issue 2, June 2009, Pages 222-228

Nabil Hayeemasae, Hanafi Ismail, Suradet Matchawet and Abdulhakim Masa (2018). Kinetic of thermal degradation and thermal stability of natural rubber filled with titanium dioxide nanoparticles, Polymer Composites, Volume40, Issue8, August 2019, Pages 3149-3155

S.M. Mirabedini and A. Kiamanesh (2013). The effect of micro and nano-sized particles on mechanical and adhesion properties of a clear polyester powder coating, Progress in Organic Coatings, Volume 76, Issue 11, November 2013, Pages 1625-1632

Wei, X., Linde, E. and Hedenqvist and M.S. (2019). Plasticiser loss from plastic or rubber products through diffusion and evaporation, npj Mater Degradation, 3, Article number: 18

Yasir Nawab, Pascal Casari, Nicolas Boyard and Frédéric Jacquemin (2017). Determination and modelling of the cure shrinkage of epoxy vinylester resin and associated composites by considering thermal gradients, Composites Science and Technology, Volume 73, 23 November 2012, Pages 81-87

Zoran S. Petrović, Ivan Javni, Alan Waddon and György Bánhegyi (2000). Structure and properties of polyurethane-silica nanocomposites, Journal of Applied Polymer Science, Volume76, Issue2, 11 April 2000, Pages 133-151 